Article

\title{
High Performance Clean Fracturing Fluid Using a New Tri-Cationic Surfactant
}

\author{
Jinzhou Zhao *, Jinming Fan, Jincheng Mao * (D), Xiaojiang Yang *, Heng Zhang \\ and Wenlong Zhang
}

State Key Laboratory of Oil and Gas Reservoir Geology and Exploitation, Southwest Petroleum University, Chengdu 610500, China; 201621000788@stu.swpu.edu.cn (J.F.); 201621000749@stu.swpu.edu.cn (H.Z.);

201711000107@stu.swpu.edu.cn (W.Z.)

* Correspondence: zhaojz@swpu.edu.cn (J.Z.); jcmao@swpu.edu.cn (J.M.);

201511000098@stu.swpu.edu.cn (X.Y.); Tel.: +86-28-8303-3546 (J.Z. \& J.M. \& X.Y.)

Received: 20 April 2018; Accepted: 5 May 2018; Published: 16 May 2018

\begin{abstract}
In order to improve the heat resistance of current clean fracturing fluids, a novel cationic surfactant (VES-T), composed of three single-chains and a spacer group, was designed and synthesized as thickener for the fluids. Various performances of such VES-T fluid in the presence of NaSal were evaluated carefully. Study of the rheological properties demonstrated that the fluids with varying concentrations ( $3-5 \mathrm{wt} \%$ ) of VES-T have excellent thermal stabilities under ultra-high temperatures ranging from 140 to $180^{\circ} \mathrm{C}$. Until now, this is the highest temperature that the VES fracturing fluid could bear. The VES-T/NaSal fluid exhibited good viscoelasticity and proppant-suspending capability, which was attributed to the three-dimensional network formed by entangled wormlike micelles. Furthermore, the VES fracturing fluids can be completely gel broken by standard brines within $2 \mathrm{~h}$. Thus, the VES-T synthesized in this work has a good prospect for utilization during the development of ultra-high temperature reservoirs.
\end{abstract}

Keywords: tri-cationic surfactant; wormlike micelles; network; fracturing fluid

\section{Introduction}

As an effective practice for increasing the rate of production of low-permeability reservoirs, hydraulic fracturing technology has been applied worldwide for decades [1]. Fracturing fluids have been utilized to generate artificial fractures in reservoir and transport proppant particles into the fracture, enhancing the conductivity of formation [2,3]. Polymer fluids such as polyacrylamide and guar gum have been widely used as thickeners for fracturing fluids. However, polymer fluids have the shortcoming of leaving non-removable residue in formation, which could plug the pore throats and cause serious formation damage $[4,5]$. In addition, due to the inherent high viscosity properties, the polymer-based fluids force the fracture to extend in height rather than in length $[6,7]$. Thus, other alternative fracturing fluids have gained great attention.

Being a substitute for conventional polymer fracturing fluid, the concept of viscoelastic surfactant (VES) fracturing fluid was first put forward by Schlumberger in 1997 [8]. Since then, VES fluids have been employed in the development of low-permeability gas and oil reservoirs for nearly 20 years [9]. Unlike polymer fracturing fluids, the sand suspension capability of the VES fluid depends largely on the elasticity instead of viscosity $[10,11]$. This unique property is rendered by the entangled wormlike micelles [12]. In general, the breaking of VES fracturing fluid after fracturing construction relies on two primary external conditions (reservoir conditions): (i) contact with hydrocarbons produced in the reservoir and (ii) dilution of reservoir brines [8,13]. Nevertheless, the VES fracturing fluid cannot break efficiently if the two reservoir conditions are not met in some cases, particularly in 
dry-gas reservoirs [14]. Usually, the internal breakers for VES fluid are used to address this problem. In comparison to traditional polymer fracturing fluid, VES fracturing fluid has a wide range of advantages, such as no insoluble residue, easy preparation in the well site, good sand-carrying capability, extremely low damage to formation, and low friction, etc. [15-17]. Furthermore, the VES foam is also applied as a treatment for ultralow-permeability reservoirs since it can reduce not only the interfacial tension but also the water consumption in the fracturing fluid [18]. In spite of the above mentioned advantages, the conventional VES fracturing fluid still has many deficiencies, which would limit its further application. For example, the traditional single head/single tail surfactants have high critical micelle concentrations (CMC) and exhibit poor surface-active behaviors. Thus, with these surfactants as thickener, the VES fracturing fluids are used at a much higher concentration than polymer fracturing fluids. Moreover, the capability of the known VES fracturing fluids to maintain high temperature and high shearing is quite limited. Meanwhile, with the rapid development of modern drilling technology, the exploitation and utilization of the ultra-high temperature oil and gas reservoirs attract tremendous attention. Accordingly, there is a great demand for VES fracturing fluids capable of resisting such high temperature.

Gemini surfactant is composed of two single head/single tail surfactants linked by a spacer between the head groups [19]. The spacer group restricts the electrostatic repulsion between hydrophilic groups through strong chemical bonds [20]. Hence, Gemini surfactants have higher surface activities and lower critical micelle concentration (CMC), exhibiting better rheological behaviors than single-chain surfactants [21,22]. Benefiting from the superiority of molecular design, the temperature resistant capacities of Gemini surfactant fracturing fluids are greatly promoted compared with single-chain surfactants. However, most of them still cannot have satisfactory performances (less than $150{ }^{\circ} \mathrm{C}$ ). Therefore, the development of VES fracturing fluid with higher temperature resistance is the popular topic of research.

In view of the excellent properties brought by the combination of two single-chain monomeric surfactants, a question that emerges is whether a surfactant molecule consisting of more monomeric surfactants could have the better performance when compared to Gemini surfactants? In this work, a novel surfactant composed of three single head/single tail surfactants was synthesized using $N, N^{\prime}$-Dimethyl-1,3-propanediamine, epichlorohydrin, and erucamidopropyl dimethylamine as raw materials. The performances of the fracturing fluid based on this surfactant, including surface activity, microstructure, viscoelasticity, thermo-shear resistance, sand suspending capability, and gel breaking property were investigated. In this way, a possible practical clean fracturing fluid could be developed for the various oilfields. It is noteworthy that, to our knowledge, this novel VES fracturing fluid could bear the highest temperature (up to $180^{\circ} \mathrm{C}$ ) till now, which is potentially useful for the exploration of deep or super deep reservoirs.

\section{Materials and Experiments}

\subsection{Materials}

The product named as VES-T was synthesized as follows. Erucamidopropyl dimethylamine was provided by Shanghai Winsono New Material Tech Co., Ltd. (Shanghai, China). N, $N^{\prime}$-Dimethyl1,3-propanediamine, epichlorohydrin, ethanol, concentrated hydrochloric acid $(\mathrm{HCl}), n$-hexane, acetone, ethyl acetate, potassium chloride $(\mathrm{KCl})$, and sodium salicylate (NaSal) were obtained from Sinopharm Chemical Reagent Co., Ltd. (Shanghai, China). Deionized water was used in all measurements.

\subsection{Synthesis of VES-T}

\subsubsection{Synthesis of Intermediate}

Ethanol $(50 \mathrm{~mL})$ and $N, N^{\prime}$-dimethyl-1,3-propanediamine $(6.13 \mathrm{~g}, 0.06 \mathrm{~mol})$ were added into a round-bottom flask. Epichlorohydrin $(27.76 \mathrm{~g}, 0.3 \mathrm{~mol})$ was then added dropwise to this stirring 
mixture at $25^{\circ} \mathrm{C}$. Subsequently, concentrated hydrochloric acid $(\mathrm{HCl})(6 \mathrm{~g}, 0.06 \mathrm{~mol})$ was added to provide hydrogen atoms for this reaction. Then, the mixture was stirred vigorously under reflux at $60{ }^{\circ} \mathrm{C}$ for $6 \mathrm{~h}$ (Scheme 1). The solvent ethanol was removed by vacuum rotary evaporator. The intermediate was extracted for three times with a mixture of deionized water and $n$-hexane (1:1) to remove residual epichlorohydrin.

\subsubsection{Synthesis of VES-T}

The intermediate $(24.97 \mathrm{~g}, 0.06 \mathrm{~mol})$ was dissolved in ethanol $(60 \mathrm{~mL})$. Then, erucamidopropyl dimethylamine $(76.14 \mathrm{~g}, 0.18 \mathrm{~mol}$ ) was added into the round-bottom flask. During the reaction process, the mixture was stirred vigorously under reflux at $85{ }^{\circ} \mathrm{C}$ for $18 \mathrm{~h}$ (Scheme 2). Next, ethanol was evaporated under reduced pressure. The crude product obtained was repeatedly washed with acetone and then recrystallized from a mixture of ethyl acetate and ethanol (7:1) for three times to yield the pure VES-T.<smiles>CN(C)CCCN</smiles>

Scheme 1. Synthesis of intermediate.

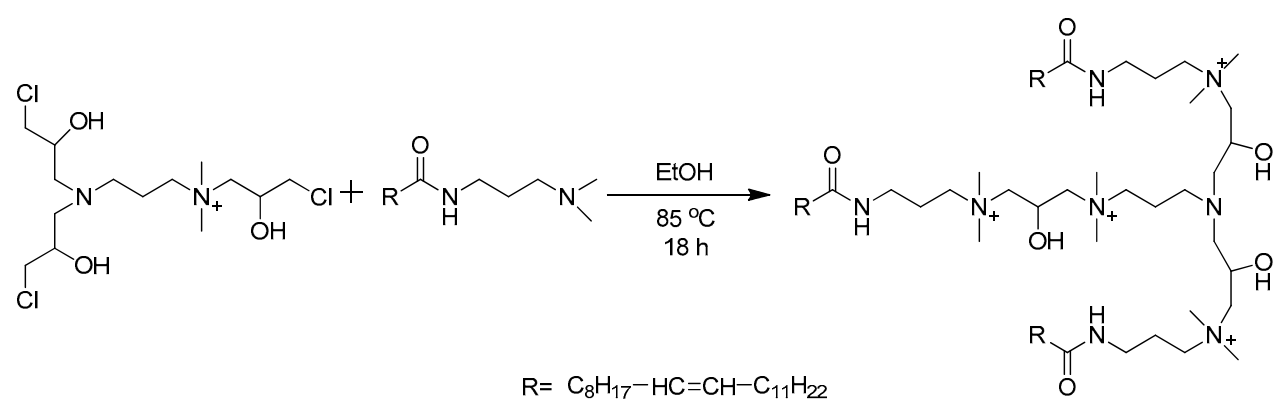

Scheme 2. Synthesis of VES-T.

\subsection{Measurement}

The ${ }^{1} \mathrm{H}$ nuclear magnetic resonance ( ${ }^{1} \mathrm{H}$ NMR) spectral analysis of VES-T was performed using a BRUKER AVANCE III HD $400 \mathrm{MHz}$ spectrometer (Bruker, Karlsruhe, Germany). Fourier-transform infrared (FT-IR) spectrum was obtained on a Nicolet MAGNA IR 560 ESP FT-IR spectrometer (Nicolet, Madison, WI, USA). The FT-IR and ${ }^{1} \mathrm{H}$ NMR spectroscopic results are shown in Figures 1 and 2.

Surface tension measurement of VES-T was conducted using KRUSS DSA30S tensiometer (KRUSS, Hamburg, Germany). Scanning electron microscope (SEM) micrographs were obtained from a Quanta 450 scanning SEM (FEI, Hillsboro, OR, USA). The samples were prepared by freezing a drop of VES-T fracturing fluid with liquid nitrogen $\left(-185^{\circ} \mathrm{C}\right)$, where the microstructure of the solutions could be retained. Subsequently, the frozen samples were dried and then coated with gold. Rheological properties were evaluated using a HAAKE MARS III Rheometer (Thermo Scientific, Munich, Germany). Viscoelasticity was determined by Anton Paar physical MCR 301 Rotational Rheometer (Anton Paar, Graz, Austria). 
Fracturing Fluid Preparation

The VES fracturing fluid mainly contains two components, wherein the VES acts as a thickener, and counter-ion additive screens the electrostatic repulsion between the hydrophilic head groups and promotes the growth of wormlike micelles. The fracturing fluids with varying concentrations ( 3 and $5 \mathrm{wt} \%$ ) of VES-T were prepared to evaluate their rheological properties, viscoelasticity, sand-carrying abilities, and gel breaking properties. The concentrations of NaSal in the two fracturing fluids were 1 and $1.2 \mathrm{wt} \%$, respectively. Additionally, the fluid sample with $\mathrm{KCl}$ as counter-ion was also prepared to investigate its effect on the formation of the network. The samples were centrifuged before tests to remove the air bubbles.

\section{Results and Discussion}

\subsection{Structural Characterization of VES-T}

The structure of VES-T was confirmed by FT-IR and ${ }^{1} \mathrm{H}$ NMR. Figure 1 shows the FT-IR spectrum of VES-T. The absorption peak resulting from $-\mathrm{O}-\mathrm{H}$ is presented at $3376.3 \mathrm{~cm}^{-1}$ and the absorption bands corresponding to the $\mathrm{CH}_{3}$ and $\mathrm{CH}_{2}$ stretch on the acylamino group are found at $2923.0 \mathrm{~cm}^{-1}$ and $2852.7 \mathrm{~cm}^{-1}$, respectively. The absorption peak at $1637.8 \mathrm{~cm}^{-1}$ is due to the $\mathrm{C}=\mathrm{O}$ stretching vibration absorptions. The $\mathrm{N}-\mathrm{H}$ stretching peak appears at $1556.1 \mathrm{~cm}^{-1}$. Moreover, the peak at $1466.3 \mathrm{~cm}^{-1}$ corresponds to $\mathrm{C}-\mathrm{N}$ stretching vibration.

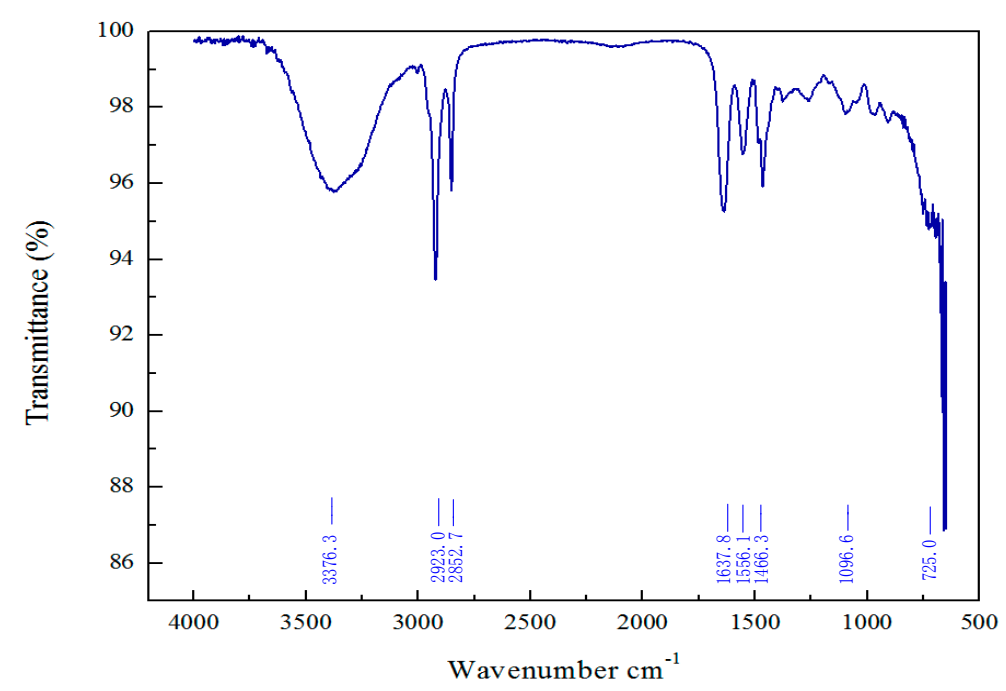

Figure 1. Fourier-transform infrared spectroscopy (FT-IR) spectra of VES-T.

Figure 2 is about the ${ }^{1} \mathrm{H}$ NMR $\left(400 \mathrm{MHz}, \mathrm{CDCl}_{3}\right)$ for VES-T: $0.88\left(\mathrm{t}, 9 \mathrm{H}, \mathrm{CH}_{3}\right), 1.26(\mathrm{~m}, 84 \mathrm{H}$, $\left.\mathrm{CH}_{2}\right), 1.58\left(\mathrm{~s}, 6 \mathrm{H}, \mathrm{COCCH}_{2}\right), 2.03-1.98\left(\mathrm{~m}, 18 \mathrm{H}, \mathrm{C}=\mathrm{CCH}_{2}, \mathrm{COCH}_{2}\right), 2.23\left(\mathrm{~m}, 8 \mathrm{H}, \mathrm{N}^{+} \mathrm{CCH}_{2}\right), 2.70(\mathrm{~s}, 6 \mathrm{H}$, $\left.\mathrm{NCH}_{2}\right), 3.47-3.35\left(\mathrm{~m}, 32 \mathrm{H}, \mathrm{N}^{+} \mathrm{CH}_{3}, \mathrm{~N}^{+} \mathrm{CH}_{2}\right), 3.72\left(\mathrm{~s}, 6 \mathrm{H}, \mathrm{CONCH}_{2}\right), 3.90\left(\mathrm{~s}, 8 \mathrm{H}, \mathrm{CN}^{+} \mathrm{CH}_{2}\right), 4.39(\mathrm{~s}, 3 \mathrm{H}$, $\mathrm{COH}), 5.07\left(\mathrm{~s}, 2 \mathrm{H}, \mathrm{N}^{+} \mathrm{CCH}\right), 5.38-5.30(\mathrm{~m}, 6 \mathrm{H}, \mathrm{HC}=\mathrm{CH}), 6.83\left(\mathrm{~s}, 1 \mathrm{H}, \mathrm{N}^{+} \mathrm{CCH}\right), 7.83(\mathrm{~m}, 3 \mathrm{H}, \mathrm{CONH})$. Thus, the desired product VES-T was successfully synthesized.

\subsection{Surface Tension Measurement}

As mentioned earlier, the surface tension of VES-T was measured at $25^{\circ} \mathrm{C}$ using a KRUSS DSA30S tensiometer. The measurement process continued until the surface tension value obtained was almost constant. Shown in Figure 3 is the variation of surface tension versus the concentration of VES-T. The variation tendency of surface tension could be described with two straight lines. The surface tension decreases with the increasing concentration of VES-T, and then reaches a clear inflection point, where the intersection of the two lines is the CMC. The surface tension at CMC is recorded as $\gamma \mathrm{CMC}$. 
As shown in Figure 3, the CMC of the corresponding product VES-T is $1.44 \times 10^{-4} \mathrm{~mol} / \mathrm{L}$ and the $\gamma \mathrm{CMC}$ is $25.98 \mathrm{mN} / \mathrm{m}$. Akram et al. [19] designed a Gemini surfactant (16-E2-16), whose CMC and $\gamma \mathrm{CMC}$ value are $1.2 \times 10^{-3} \mathrm{~mol} / \mathrm{L}$ and $42.6 \mathrm{mN} / \mathrm{m}$, respectively. Apparently, the CMC and $\gamma \mathrm{CMC}$ of VES-T are both smaller than that of 16-E2-16, which is consistent with the previous assumption that the surfactant composed of three hydrophobic groups has a better performance than general Gemini surfactants.

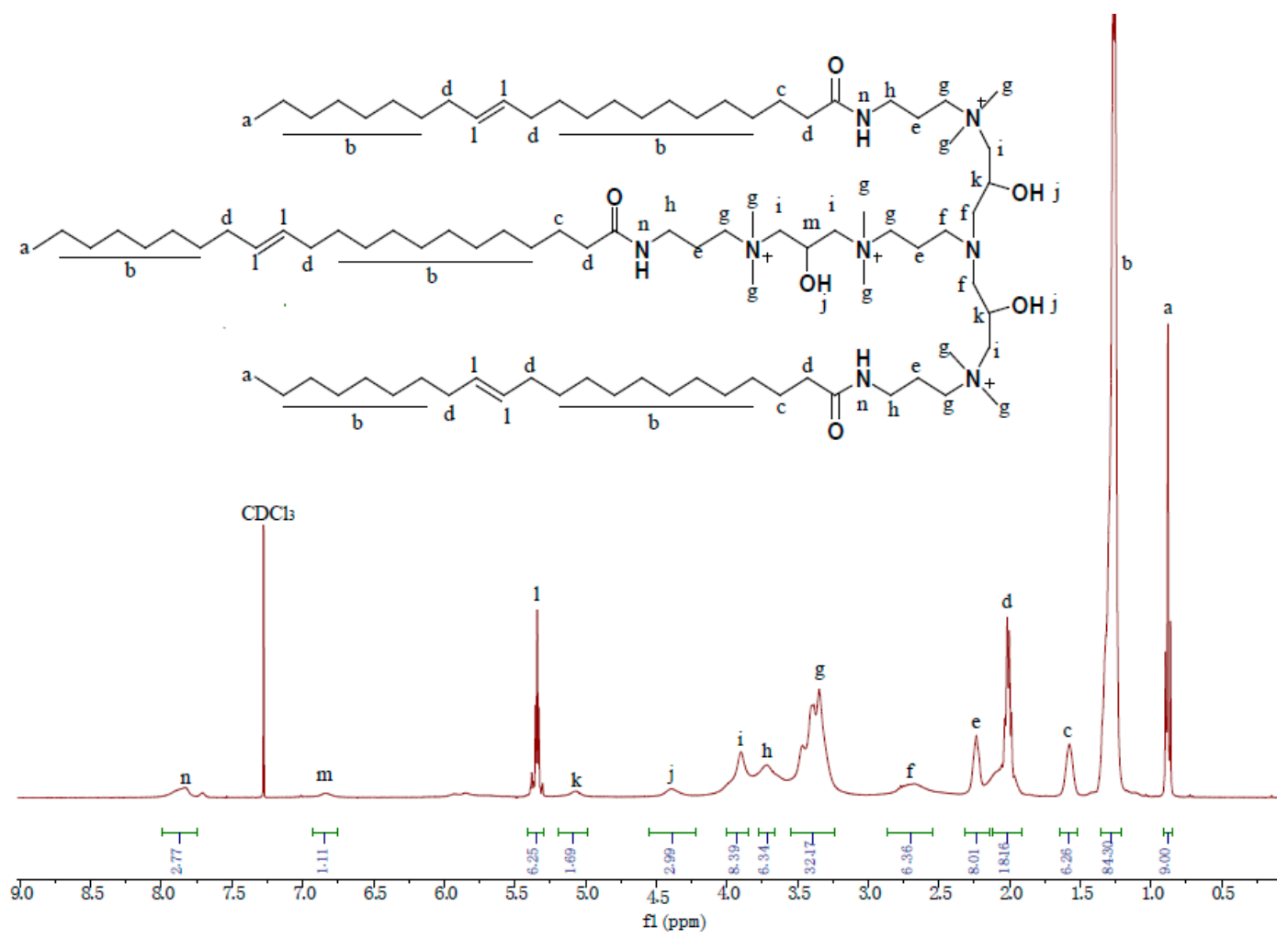

Figure 2. ${ }^{1} \mathrm{H}$ NMR spectrum of VES-T in $\mathrm{CDCl}_{3}$.

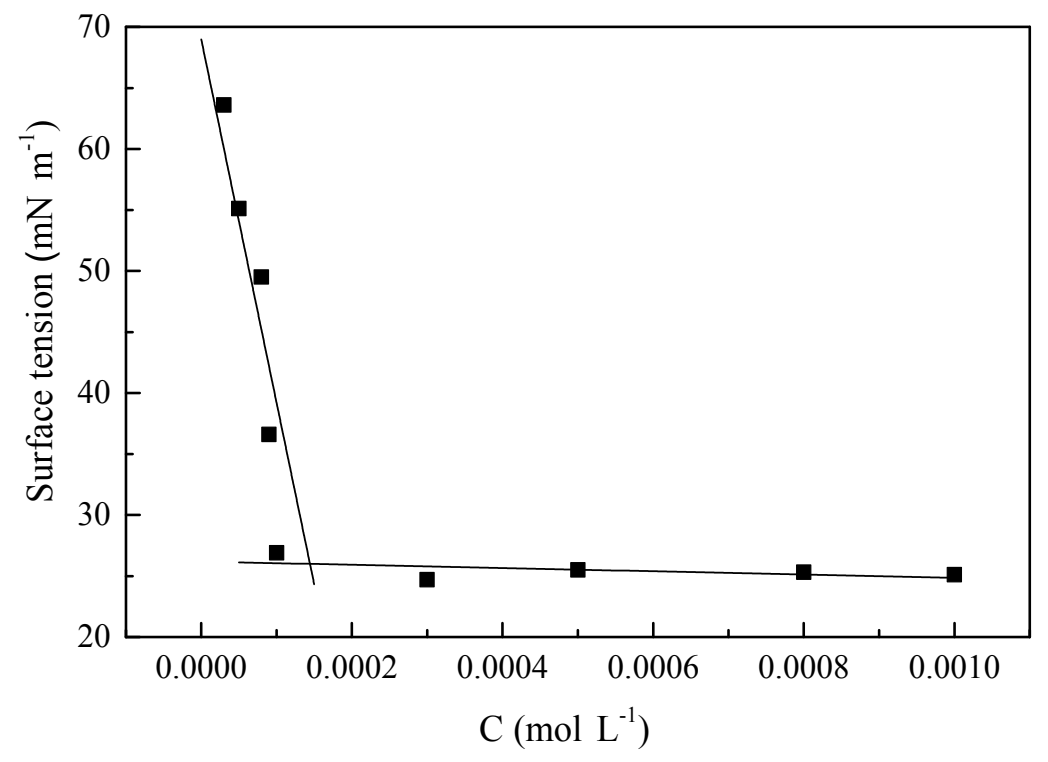

Figure 3. Surface tension plot for VES-T tri-cationic surfactant. 


\subsection{Scanning Electron Microscopy (SEM)}

As SEM visualizes the micellar morphology directly, it was employed to investigate the microstructure of the VES-T fracturing fluid, which could also associate the microstructure with macroscopic properties, such as the rheology and viscoelasticity of the VES-T fracturing fluid [23]. According to Candau et al. [20], the self-aggregation and entanglement of surfactant micelles largely depend on the nature and concentration of salts. The salts would help transform spherical micelles into rod-like or wormlike micelles [24,25].

For this reason, the SEM measurements of the VES-T fracturing fluids without any counter-ion, with $\mathrm{NaSal}$ and $\mathrm{KCl}$ were conducted using a Quanta 450 scanning SEM (FEI, Hillsboro, OR, USA), respectively. The results are shown in Figure $4 \mathrm{a}-\mathrm{c}$. Compared with Figure $4 \mathrm{a}, \mathrm{b}$ and $\mathrm{c}$ both show cross-linked networks composed of entangled wormlike micelles. This result confirms that the presences of counter-ions ( $\mathrm{NaSal}$ and $\mathrm{KCl}$ ) greatly assist the formation of $3 \mathrm{D}$ networks, and the shielding effects by overhead counter-ions are remarkable. The viscoelastic and rheological characters of the VES-T fracturing fluid can be explained as the formation of the 3D network.

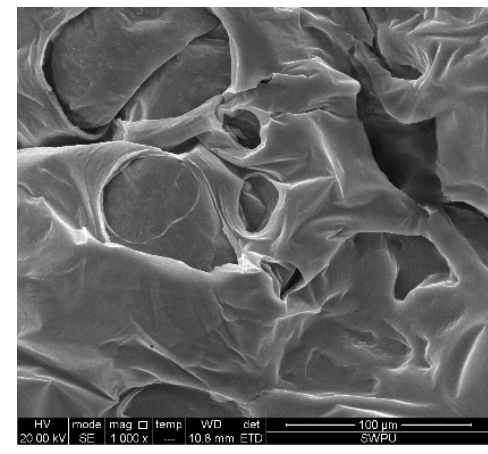

(a)

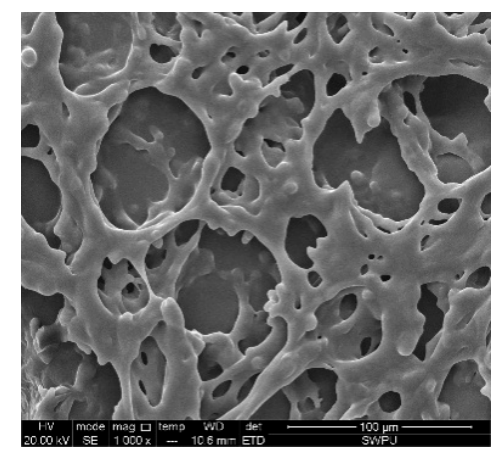

(b)

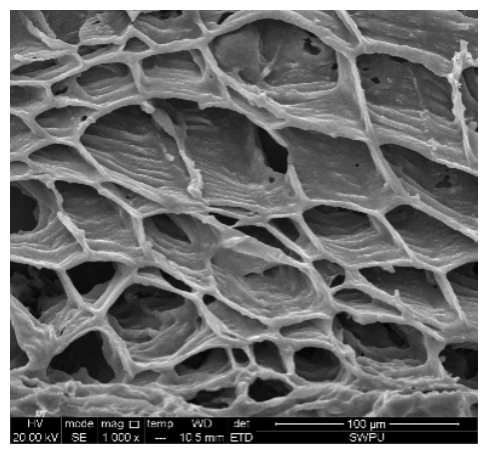

(c)

Figure 4. The Scanning electron microscopy (SEM) images of (a) VES-T solution without any counter-ion (served as a blank control); (b) VES-T solution with NaSal; (c) VES-T solution with KCl. The cross-linked networks could be observed in both (b) and (c) in comparison to (a).

\subsection{Resistance to High Temperature and High Shear}

Both $\mathrm{KCl}$ and $\mathrm{NaSal}$ have significant effects on the formation of entangled wormlike micelles according to the SEM morphologies of Figure 4a-c. For the purpose of investigating the influence of the counter-ions on the macroscopic rheological properties of the VES-T fluids, the thermal-stability tests for the VES-T fluids with $\mathrm{KCl}$ and NaSal were performed at $160^{\circ} \mathrm{C}$ and at the constant shear rate of $170 \mathrm{~s}^{-1}$ for $80 \mathrm{~min}$. The results are shown in Figures 5 and 6 . As depicted in Figure 5, the viscosity of the solution prepared with $5 \mathrm{wt} \%$ VES-T and $1.4 \mathrm{wt} \% \mathrm{KCl}$ first decreases to $433 \mathrm{mPa} \cdot \mathrm{s}$, and then increases to $458 \mathrm{mPa} \cdot \mathrm{s}$. Subsequently, the viscosity decreases again and finally maintains at about $50 \mathrm{mPa} \cdot \mathrm{s}$. Similarly, for a solution consisting of $5 \mathrm{wt} \%$ VES-T and $1.2 \mathrm{wt} \% \mathrm{NaSal}$, the viscosity of fluid decreases sharply with the increase of testing temperature, and then maintains at about $78 \mathrm{mPa} \cdot \mathrm{s}$. The results indicate that NaSal has a superior performance in enhancing the thermal stability of the system compared with $\mathrm{KCl}$.

In view of the excellent rheological property that VES-T/NaSal solution exhibited at $160{ }^{\circ} \mathrm{C}$, the thermal stability test was further conducted at $180^{\circ} \mathrm{C}$. As depicted in Figure 7, the VES-T/NaSal solution displays a similar rheological behavior to that at $160^{\circ} \mathrm{C}$, and the viscosity is constant at about $42 \mathrm{mPa} \cdot \mathrm{s}$ till the end of test. Obviously, NaSal is more suitable to be the counter-ion of the system. 


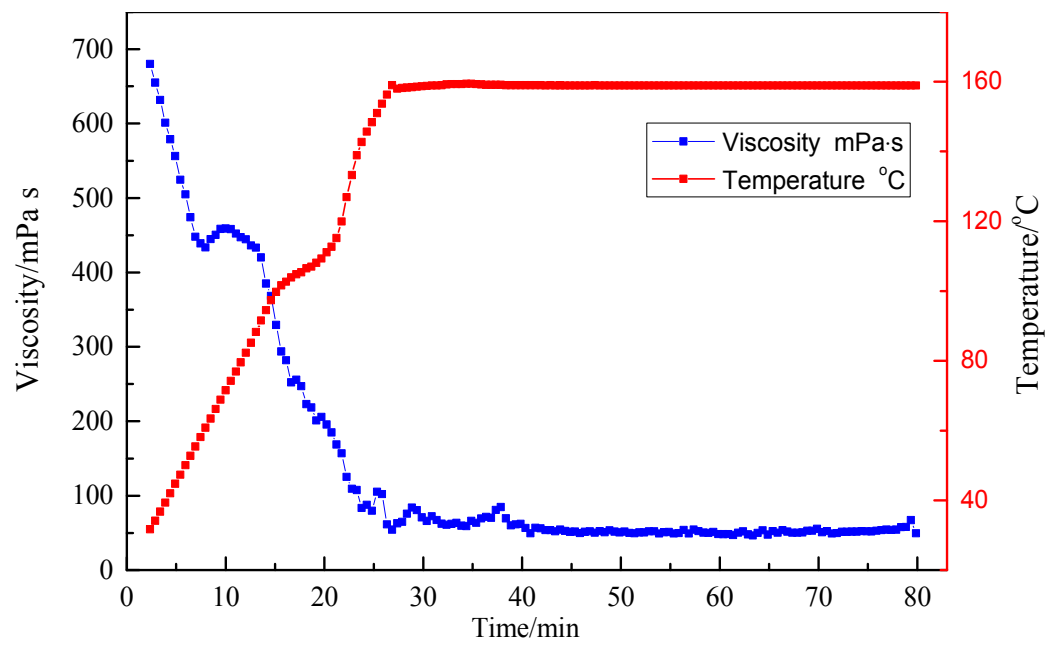

Figure 5. Shear resistance of $5 \mathrm{wt} \%$ VES-T with $1.4 \mathrm{wt} \% \mathrm{KCl}$ fracturing fluid at $160{ }^{\circ} \mathrm{C}, 170 \mathrm{~s}^{-1}$.

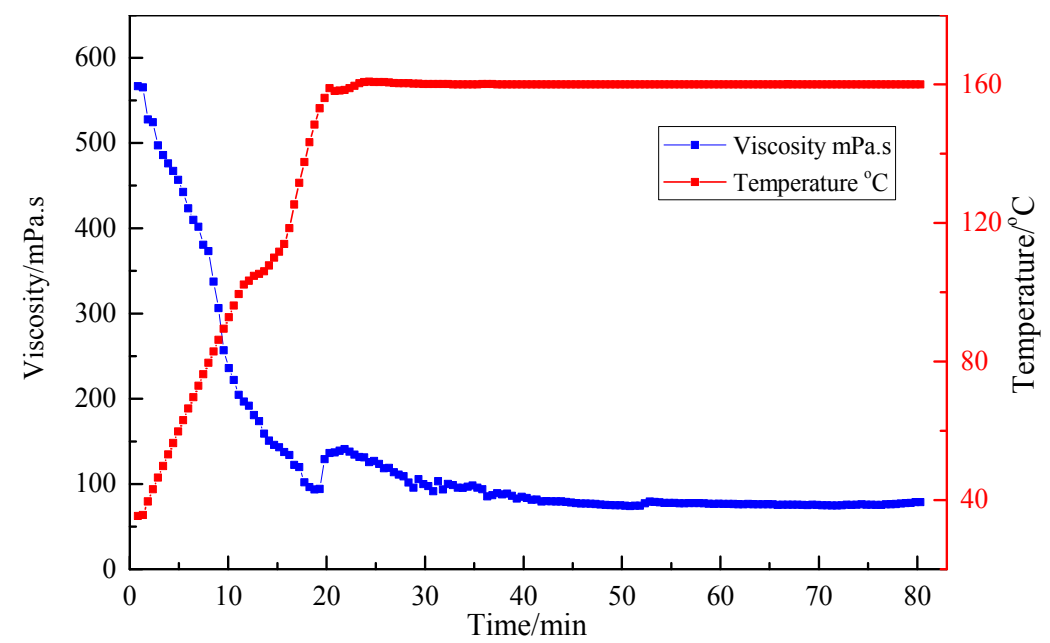

Figure 6. Shear resistance of $5 \mathrm{wt} \%$ VES-T with $1.2 \mathrm{wt} \% \mathrm{NaSal}$ fracturing fluid at $160{ }^{\circ} \mathrm{C}, 170 \mathrm{~s}^{-1}$.

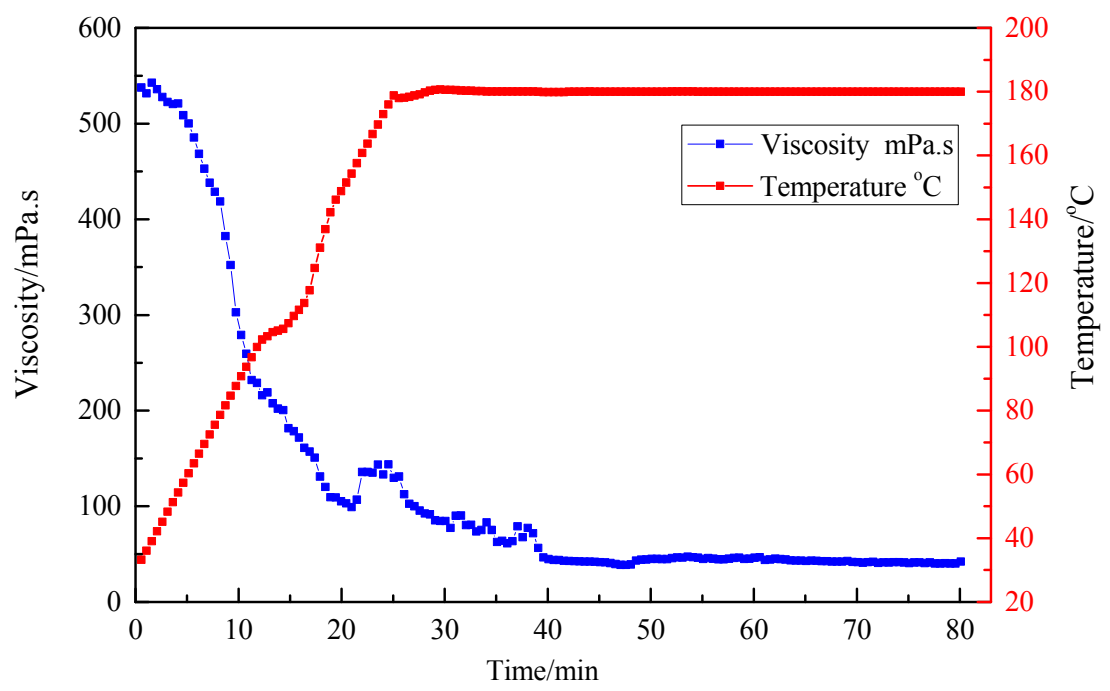

Figure 7. Shear resistance of $5 \mathrm{wt} \%$ VES-T with $1.2 \mathrm{wt} \% \mathrm{NaSal}$ fracturing fluid at $180{ }^{\circ} \mathrm{C}, 170 \mathrm{~s}^{-1}$. 
To reduce the cost, the concentration of VES-T was reduced to $3 \mathrm{wt} \%$, and the rheological property of the system was evaluated at $140{ }^{\circ} \mathrm{C}$. As shown in Figure 8, the viscosity of the $3 \mathrm{wt} \%$ VES-T/ $1 \mathrm{wt} \%$ NaSal solution remains at $70 \mathrm{mPa} \cdot \mathrm{s}$, which could meet the viscosity requirement ( $>25 \mathrm{mPa} \cdot \mathrm{s})$ for VES fracturing fluid according to industry standard. The thermal-stability testing results demonstrate that the VES-T fracturing fluids with the above formula could have good performance in the development of reservoirs under ultra-high temperature.

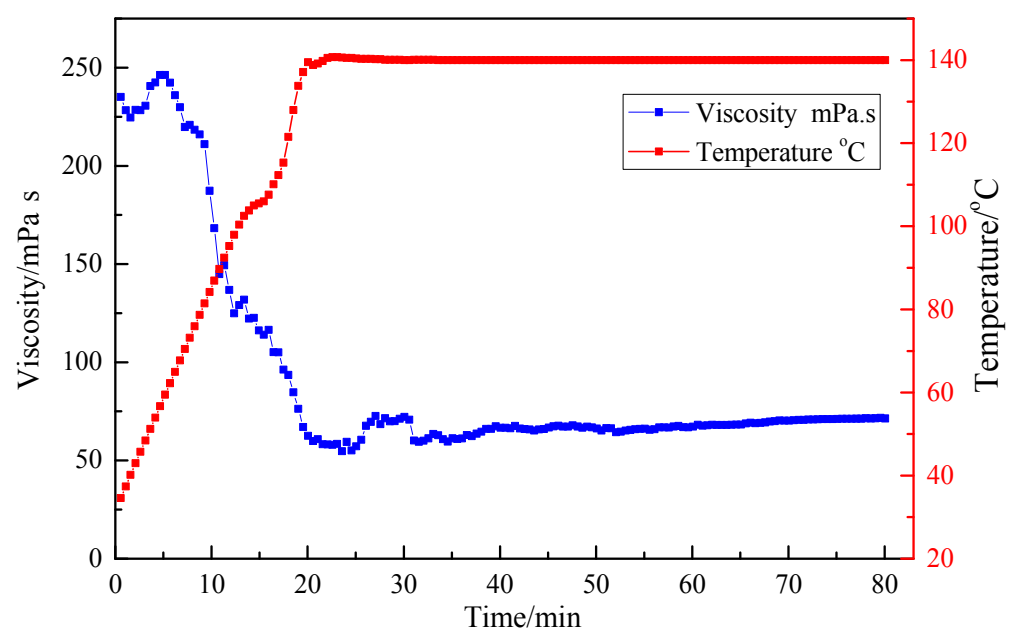

Figure 8. Shear resistance of $3 \mathrm{wt} \%$ VES-T with $1 \mathrm{wt} \% \mathrm{NaSal}$ fracturing fluid at $140{ }^{\circ} \mathrm{C}, 170 \mathrm{~s}^{-1}$.

Some studies reported that both chlorides and aromatic compounds, such as $\mathrm{KCl}$ and NaSal, could induce micelle morphology transition for cationic surfactant from spherical to wormlike [26-34]. However, there are some differences between the effects of $\mathrm{KCl}$ and NaSal. Chlorine anions $\left(\mathrm{Cl}^{-}\right)$are adsorbed on the surface of the cationic hydrophilic head group to form an electric double layer around the micelle shell, which screens the electrostatic repulsion. Alternatively, in addition to the similar surface adsorption of $\mathrm{Cl}^{-}$, the aromatic anion $\left(\mathrm{Sal}^{-}\right)$penetrates the surface of the micelle, whose aromatic nucleus has a strong hydrophobic interaction with the surfactant, increasing the surfactant-packing parameter by efficiently decreasing the area per surfactant monomer $\left(a_{0}\right)[28,29,31]$. Therefore, $\mathrm{Sal}^{-}$is a far more effective driving force to the growth of the worm-like micelles. The mechanism by which $\mathrm{Sal}^{-}$and $\mathrm{Cl}^{-}$affect the micelle shape transition is schematically illustrated in Figure $9 \mathrm{a}, \mathrm{b}$, respectively. Additionally, the sphere-rod transition of micelles generally occurs with the lower addition of Sal ${ }^{-}$ than $\mathrm{Cl}^{-}[28,30,32-34]$, which agrees well with the experimental results.

(a)

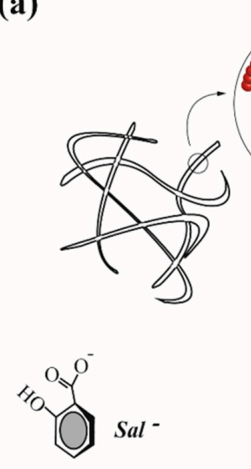

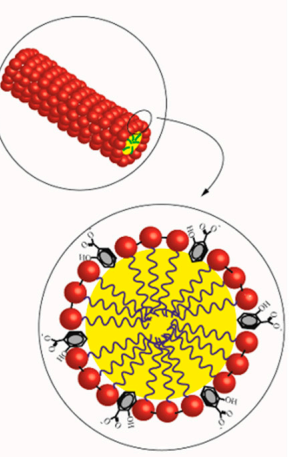

(b)

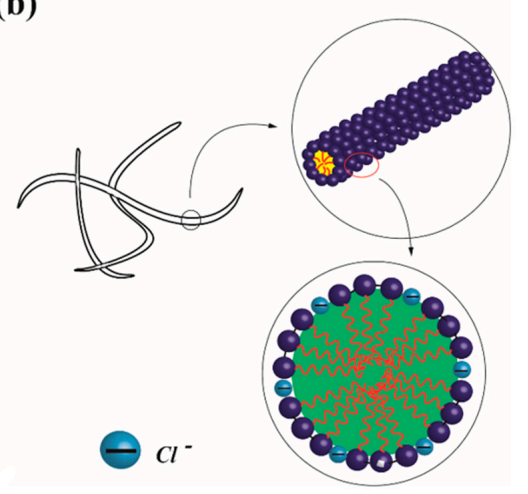

Figure 9. (a) Schematic diagram for $\mathrm{Sal}^{-}$to affect micelle shape transition; (b) Schematic diagram for $\mathrm{Cl}^{-}$to affect micelle shape transition. 


\subsection{Viscoelasticity Evaluation}

Compared with traditional viscous fluids, the proppant suspension of VES fracturing fluid is strongly affected by both viscosity and elasticity, that is, the viscoelasticity. Viscoelasticity is an essential property to evaluate the performance of VES fracturing fluid, which is attributed to the formation of a 3D network. Therefore, the viscoelasticity of the VES-T solution in the presence of NaSal was measured by an Anton Paar physical MCR 301 Rotational Rheometer, as shown in Figure 10.

In each solution, storage modulus $G^{\prime}$ and loss modulus $G^{\prime \prime}$ both slightly increase with the increase of frequency during the range of frequency scanning, and storage modulus $G^{\prime}$ is greater than loss modulus $G^{\prime \prime}$ throughout the test. Accordingly, the two solutions both exhibit typical elastic behaviors, indicating the formation of entangled wormlike micelles. Moreover, it is apparent that the storage modulus $G^{\prime}$ and loss modulus $G^{\prime \prime}$ of the VES solution both increase with the increasing concentration of VES-T from $3 \mathrm{wt} \%$ to $5 \mathrm{wt} \%$, which demonstrates that the increasing VES-T concentration in the presence of NaSal augments the entanglements. The increase of VES concentration results in a more obvious viscoelasticity of the VES fracturing fluid [35].

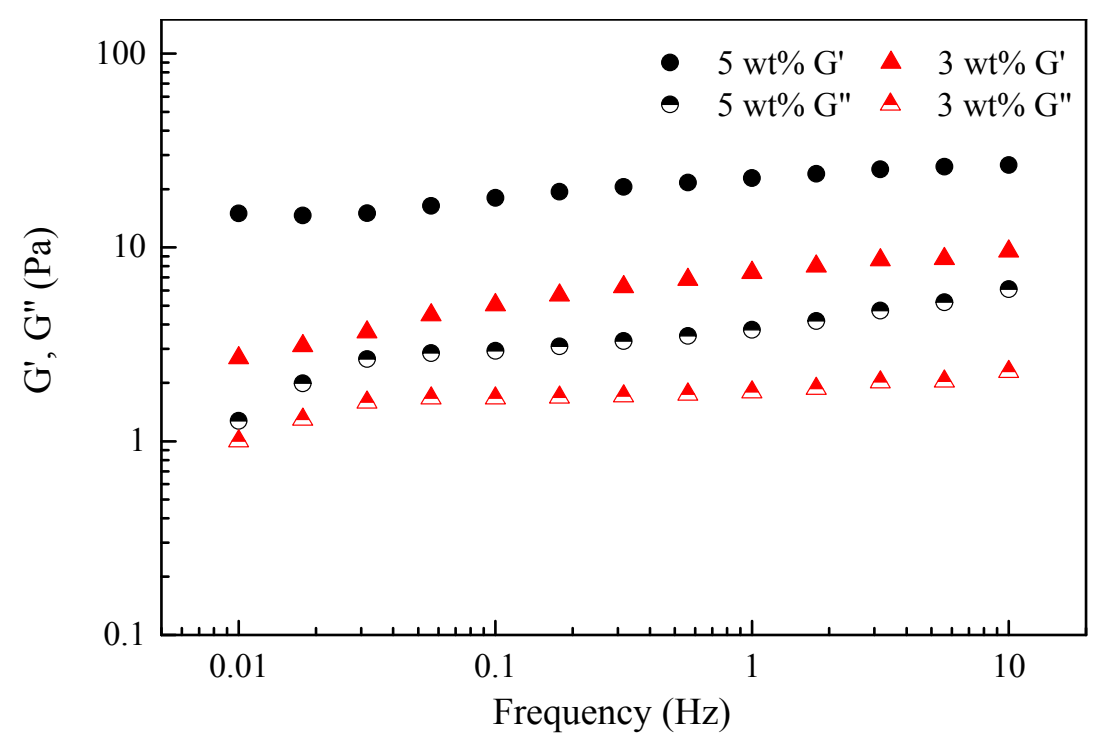

Figure 10. Storage modulus $G^{\prime}$ and loss modulus $G^{\prime \prime}$ varying as a function of frequency for the two ( $3 \mathrm{wt} \%$ and $5 \mathrm{wt} \%$ ) VES-T samples at $25^{\circ} \mathrm{C}$. $\mathrm{G}^{\prime}$ is greater than $\mathrm{G}^{\prime \prime}$ throughout the test in both the two samples. $G^{\prime}$ and $G^{\prime \prime}$ of the $5 \mathrm{wt} \%$ VES-T sample are greater than that of the $3 \mathrm{wt} \%$ VES-T sample.

\subsection{Proppant Suspension Measurement}

Good sand-carrying capability is essential to the fracturing fluid, which allows it to carry proppant evenly into the fractures [36]. If the sand-carrying capability of the fracturing fluid is poor, the proppant will fall rapidly and cannot be transported into deep fractures in the reservoir [37]. The static proppant settling tests for the VES-T fracturing fluids with abovementioned formula were carried out at $80^{\circ} \mathrm{C}$ to evaluate the sand-carrying capabilities. $50 \mathrm{~mL}$ of VES fluid and $10 \mathrm{~g}$ of ceramics of mesh size 20/40 were mixed uniformly and then poured into a $50 \mathrm{~mL}$ graduated cylinder. After 120 min under the experimental conditions, almost no ceramics settled in $5 \mathrm{wt} \%$ VES-T/1.2 $\mathrm{wt} \% \mathrm{NaSal}$ fluid. For the fluid sample with $3 \mathrm{wt} \%$ VES-T, a small amount of proppant settled and the settling velocity was $0.007 \mathrm{~mm} / \mathrm{s}$. The proppant settlement phenomenon was more obvious in fluid with lower VES-T concentration. When the experiments were conducted at $25{ }^{\circ} \mathrm{C}$, few proppant settled in both the two fluid samples after $2 \mathrm{~d}$. Thus, the fracturing fluids with above formula could meet the demand for suspending proppant during the fracturing construction. The proppant suspension of the VES fracturing fluid depends on both viscosity and elasticity of the system, which is quite different from that of the polymer and guar gum fracturing fluids. 


\subsection{Gel Breaking Test}

The gel breaking process must be completed rapidly and thoroughly after fracturing construction to minimize the damage to the reservoir. Generally, the fracturing fluid is considered to be completely broken once the viscosity of the breaking fluid is less than $5 \mathrm{mPa} \cdot \mathrm{s}$. VES fracturing fluid usually relies on reservoir conditions such as standard brines and hydrocarbons to achieve the purpose of gel breaking. Hence, the VES-T fracturing fluids with the above formula were mixed separately with different proportions of standard brine and kerosene at $90{ }^{\circ} \mathrm{C}$. As shown in Tables 1 and 2, when the weight ratios are higher than 1:4 (standard brine to $3 \mathrm{wt} \%$ VES fluid) and 1:10 (standard brine to $5 \mathrm{wt} \%$ VES fluid), the fracturing fluids are completely broken and the viscosities of the breaking fluids are both less than $5 \mathrm{mPa} \cdot \mathrm{s}$ within $2 \mathrm{~h}$. Moreover, it is found that the VES-T fracturing fluid breaks quicker with the higher volume ratio of brine. For the reservoir hydrocarbon condition, when $30 \mathrm{wt} \%$ of kerosene is added, the viscosities of fluids with above formula are below $3 \mathrm{mPa} \cdot \mathrm{s}$ within $30 \mathrm{~min}$.

Table 1. 3 wt \% viscoelastic surfactant (VES) fluid gel breaking at different brine ratios.

\begin{tabular}{ccc}
\hline Ratio (Standard Brine to Fluid) & Breaking Time (h) & Viscosity of Breaking Fluid (mPa·s) \\
\hline $1: 5$ & 2.3 & 4.9 \\
$1: 4$ & 1.8 & 4.1 \\
$1: 3$ & 1.1 & 3.1 \\
\hline
\end{tabular}

Table 2. $5 \mathrm{wt} \%$ VES fluid gel breaking at different brine ratios.

\begin{tabular}{ccc}
\hline Ratio (Standard Brine to Fluid) & Breaking Time (h) & Viscosity of Breaking Fluid (mPa.s) \\
\hline $1: 12$ & 2.6 & 4.3 \\
$1: 10$ & 1.9 & 3.8 \\
$1: 8$ & 1.3 & 2.9 \\
\hline
\end{tabular}

These results confirm that the gel breaking properties of the VES fluids of the above formula are sufficient to fulfill the requirements for flowback treatment of fracturing fluid.

\subsection{General Description}

The tri-cationic surfactant (VES-T) developed as a thickener for clean fracturing fluid was synthesized in a simple way with high yield $(>96 \%)$. As far as we know, this is the first example of tri-cationic surfactant for the fracturing fluid. The main feedstock used in synthesis of the VES-T is erucic acid, which comes from the rapeseed. Thus, it is environmental friendly. The heat resistance of the VES-T fracturing fluid far exceeds that of the majority of the existing VES fracturing fluids. For instance, the $2 \%$ erucyldimethyl amidopropyl amine oxide (EMAO) solution cannot have good performance over $90^{\circ} \mathrm{C}$ [38]. A VES-HT fracturing fluid could only fulfill the requirement of $275^{\circ} \mathrm{F}$ $\left(135^{\circ} \mathrm{C}\right)$ according to Schlumberger [39]. Nevertheless, compared with the generally used single-chain and Gemini surfactants, the molecule of VES-T consists of more monomeric surfactants, and the price of erucic acid is higher than commonly used raw materials such as oleic acid, which would slightly increase the cost. However, if the rapeseed could be directly employed as the starting material, the cost will be reduced sharply. Work is ongoing in our lab to further optimize the formula to reduce the amount of VES.

\section{Conclusions}

A novel surfactant consisting of three single head/single tail surfactants was synthesized as thickener for VES fracturing fluid. The product was characterized by ${ }^{1} \mathrm{H}$ NMR and FT-IR. The two optimized formula of VES fracturing fluids were determined to be $5 \mathrm{wt} \%$ VES-T $+1.2 \mathrm{wt} \% \mathrm{NaSal}$ and $3 \mathrm{wt} \% \mathrm{VES}-\mathrm{T}+1 \mathrm{wt} \% \mathrm{NaSal}$, and both of them have excellent performances in various tests. 
(1). The surface tension measurement data confirm that the combination of three single-chain surfactants leads to a lower CMC and higher surface activity than the conventional Gemini surfactants.

(2). Microstructure study suggests that the organic (NaSal) and inorganic $(\mathrm{KCl})$ salts both have significant effects on the micellar transition from spherical micelles to wormlike micelles.

(3). The fracturing fluids with the two concentrations (3 and $5 \mathrm{wt} \%$ ) of VES-T both exhibit excellent rheological properties under high temperature. Especially, the viscosity of fluid sample containing $5 \mathrm{wt} \%$ VES-T and $1.2 \mathrm{wt} \%$ NaSal maintains at about $42 \mathrm{mPa} \cdot \mathrm{s}$ at $180{ }^{\circ} \mathrm{C}$, which is the highest temperature recorded till now.

(4). Viscoelasticity evaluation shows typical elastic properties of the two fracturing fluids. Additionally, the storage modulus $G^{\prime}$ and loss modulus $G^{\prime \prime}$ of the VES solution both increased with the increasing concentration of VES-T, indicating a more obvious viscoelasticity of the VES fracturing fluid. In other words, a higher VES concentration leads to a stronger network structure.

The two developed VES fracturing fluids also have many other advantages, such as strong sand suspending abilities and easy gel breaking, etc. These benefits demonstrate that the synthesized product can be a promising application in the development of gas and oil reservoirs with ultra-high temperature.

Author Contributions: J.Z., J.M. and H.Z. conceived and designed the experiments; J.F., X.Y. and W.Z. performed the experiments; J.Z. and J.F. analyzed the data; J.M. contributed reagents/materials/analysis tools and supervised all the works; all authors wrote the paper.

Acknowledgments: The authors are grateful to Sichuan Youth Science \& Technology Foundation (2017JQ0010), National High Technology Research \& Development Program (2016ZX05053), Key Fund Project of Educational Commission of Sichuan Province (16CZ0008), Explorative Project Fund (G201601) of State Key Laboratory of Oil and Gas Reservoir Geology and Exploitation (Southwest Petroleum University), the Major Program of the National Natural Science Foundation of China (51490653) and 973 Program (2013CB228004).

Conflicts of Interest: The authors declare no conflict of interest.

\section{References}

1. Montgomery, C.T.; Smith, M.B. Hydraulic fracturing: History of an enduring technology. J. Petrol. Technol. 2010, 62, 26-32. [CrossRef]

2. Waters, G.A.; Dean, B.K.; Downie, R.C.; Kerrihard, K.; Austbo, L.; Mcpherson, B. Simultaneous Hydraulic Fracturing of Adjacent Horizontal Wells in the Woodford Shale. In Proceedings of the SPE Hydraulic Fracturing Technology Conference, The Woodlands, TX, USA, 19-21 January 2009.

3. Yang, C.; Hu, Z.; Song, Z.; Bai, J.; Zhang, Y.; Luo, J.; Du, Y.; Jiang, Q. Self-assembly properties of ultra-long-chain Gemini surfactant with high performance in a fracturing fluid application. J. Appl. Polym. Sci. 2017, 134, 44602. [CrossRef]

4. Marec, A.; Thomas, J.H.; Guerjouma, R.E. Damage characterization of polymer-based composite materials: Multivariable analysis and wavelet transform for clustering acoustic emission data. Mech. Syst. Signal Process. 2008, 22, 1441-1464. [CrossRef]

5. Yang, J.; Guan, B.; Lu, Y.; Cui, W.; Qiu, X.; Yang, Z.; Qin, W. Viscoelastic Evaluation of Gemini Surfactant Gel for Hydraulic Fracturing. In Proceedings of the SPE European Formation Damage Conference \& Exhibition, Noordwijk, The Netherlands, 5-7 June 2013.

6. Samuel, M.; Dan, P.; Graham, D.; Kordziel, W.; Waters, G.; Waite, T.; Vinod, P.S.; Fu, D.; Downey, R. Viscoelastic Surfactant Fracturing Fluids: Applications in Low Permeability Reservoirs. In Proceedings of the SPE Rocky Mountain Regional/Low-Permeability Reservoirs Symposium and Exhibition, Denver, CO, USA, 12-15 March 2000.

7. Barbati, A.C.; Desroches, J.; Robisson, A.; Mckinley, G.H. Complex Fluids and Hydraulic Fracturing. Annu. Rev. Chem. Biomol. 2016, 7, 415-453. [CrossRef] [PubMed]

8. Samuel, M.M.; Card, R.J.; Nelson, E.B.; Brown, J.E.; Vinod, P.S.; Temple, H.L.; Qu, Q.; Fu, D.K. Polymer-Free Fluid for Fracturing Applications. SPE Drill. Complet. 1999, 14, 240-246. [CrossRef]

9. Nasr-El-Din, H.A.; Li, L.; Crews, J.B.; Cawiezel, K.E. Impact of Organic Acids/Chelating Agents on the Rheological Properties of an Amidoamine-Oxide Surfactant. SPE Prod. Oper. 2010, 26, 30-40. [CrossRef] 
10. Malhotra, S.; Sharma, M.M. A General Correlation for Proppant Settling in VES Fluids. In Proceedings of the SPE Hydraulic Fracturing Technology Conference, The Woodlands, TX, USA, 24-26 January 2011.

11. Wang, Z.; Wang, S.; Jing, Z.; Luo, X. Viscoelastic Drag of Particles Settling in Wormlike Micellar Solutions of Varying Surfactant Concentration. J. Dispers. Sci. Technol. 2016, 37, 442-449. [CrossRef]

12. Brown, J.E.; Lee, R.; Nelson, E.B.; Ali, S.A. Use of a Viscoelastic Carrier Fluid in Frac-Pack Applications. In Proceedings of the SPE Formation Damage Control Symposium, Lafayette, LA, USA, 14-15 February 1996.

13. Samuel, M.; Card, R.; Nelson, E.; Brown, J.E.; Vinod, P.S.; Temple, H.L.; Qu, Q.; Fu, D.K. Polymer-free fluid for hydraulic fracturing. In Proceedings of the SPE Annual Technical Conference and Exhibition, San Antonio, TX, USA, 5-8 October 1997.

14. Crews, J.B.; Huang, T.; Wood, W.R. New Fluid Technology Improves Performance and Provides a Method To Treat High-Pressure and Deepwater Wells. In Proceedings of the SPE Annual Technical Conference and Exhibition, San Antonio, TX, USA, 24-27 September 2006.

15. Fontana, C.; Muruaga, E.; Perez, D.R.; Cavazzoli, G.D.; Krenz, A. Successful Application of a High Temperature Viscoelastic Surfactant (VES) Fracturing Fluids under Extreme Conditions in Patagonian Wells, San Jorge Basin. In Proceedings of the EUROPEC/EAGE Conference and Exhibition, London, UK, 11-14 June 2007.

16. Gu, M.; Mohanty, K.K. Rheology of polymer-free foam fracturing fluids. J. Pet. Sci. Eng. 2015, 134, 87-96. [CrossRef]

17. Barati, R.; Liang, J.T. A review of fracturing fluid systems used for hydraulic fracturing of oil and gas wells. J. Appl. Polym. Sci. 2014, 131, 318-323. [CrossRef]

18. Cawiezel, K.E.; Gupta, D.V.S. Successful Optimization of Viscoelastic Foamed Fracturing Fluids with Ultralightweight Proppants for Ultralow-Permeability Reservoirs. SPE Prod. Oper. 2010, 25, 80-88. [CrossRef]

19. Akram, M.; Bhat, I.A.; KabirudDin. Self-aggregation of surfactant ethane-1,2-diyl bis $(N, N$-dimethyl- $N$ hexadecylammoniumacetoxy) dichloride: Tensiometric, microscopic, and spectroscopic studies. J. Phys. Chem. B 2015, 119, 3499-3509. [CrossRef] [PubMed]

20. Kern, F.; Lequeux, F.; Zana, R.; Candau, S.J. Dynamic Properties of Salt-Free Viscoelastic Micellar Solutions. Langmuir 1994, 10, 1714-1723. [CrossRef]

21. Li, Q.; Yue, X.; Shang, P.; Quan, Y.; Ren, M.; Ma, Y.; Chen, X. Environmental stimuli induced phase transition in the aqueous mixture solution of Gemini surfactants and sodium deoxycholate. Colloids Surf. A 2016, 489, 67-74. [CrossRef]

22. Mao, J.; Yang, X.; Wang, D.; Li, Y.; Zhao, J. A Novel Gemini Viscoelastic Surfactant (VES) for Fracturing Fluid with Good Temperature Stability. RSC Adv. 2016, 6, 88426-88432. [CrossRef]

23. Yan, Z.; Dai, C.; Zhao, M.; Sun, Y.; Zhao, G. Development, formation mechanism and performance evaluation of a reusable viscoelastic surfactant fracturing fluid. J. Ind. Eng. Chem. 2016, 37, 115-122. [CrossRef]

24. Khatory, A.; Lequeux, F.; Kern, F.; Candau, S.J. Linear and nonlinear viscoelasticity of semidilute solutions of wormlike micelles at high salt content. Langmuir 1993, 9, 1456-1464. [CrossRef]

25. Mu, J.; Li, G.; Jia, X.; Wang, H.; Zhang, G. Rheological Properties and Microstructures of Anionic Micellar Solutions in the Presence of Different Inorganic Salts. J. Phys. Chem. B 2002, 106, 622-643. [CrossRef]

26. Hartmann, V.; Cressely, R. Simple salts effects on the characteristics of the shear thickening exhibited by an aqueous micellar solution of CTAB/NaSal. EPL 2007, 40, 691. [CrossRef]

27. Imae, T.; Ikeda, S. Characteristics of rodlike micelles of cetyltrimethylammonium chloride in aqueous $\mathrm{NaCl}$ solutions: Their flexibility and the scaling laws in dilute and semi dilute regimes. Colloid Polym. Sci. 1987, 265, 1090-1098. [CrossRef]

28. And, L.J.M.; Han, Z.; Warr, G.G.; Cassidy, M.A.; Butler, P.D.; Hamilton, W.A. Effect of Counterion Competition on Micellar Growth Horizons for Cetyltrimethylammonium Micellar Surfaces: Electrostatics and Specific Binding. J. Phys. Chem. B 1997, 101, 7919-7927.

29. Maillet, J.B.; Lachet, V.; Coveney, P.V. Large scale molecular dynamics simulation of self-assembly processes in short and long chain cationic surfactants. Phys. Chem. Chem. Phys. 1999, 1, 5277-5290. [CrossRef]

30. And, S.R.R.; Kaler, E.W. Highly Viscoelastic Wormlike Micellar Solutions Formed by Cationic Surfactants with Long Unsaturated Tails. Langmuir 2007, 17, 300-306.

31. Mohanty, S.; Davis, H.T.; Mccormick, A.V. Complementary Use of Simulations and Free Energy Models for CTAB/NaSal Systems. Langmuir 2015, 17, 7160-7171. [CrossRef] 
32. Clausen, T.M.; Vinson, P.K.; Minter, J.R.; Davis, H.T.; Talmon, Y.; Miller, W.G. Viscoelastic micellar solutions: Microscopy and rheology. J. Phys. Chem. 1992, 1, 474-484. [CrossRef]

33. And, W.J.K.; Yang, S.M. Flow-Induced Silica Structure during in Situ Gelation of Wormy Micellar Solutions. Langmuir 2000, 16, 4761-4765.

34. Vasudevan, M.; Shen, A.; Khomami, B.; Sureshkumar, R. Self-similar shear thickening behavior in CTAB/NaSal surfactant solutions. J. Rheol. 2007, 52, 527-550. [CrossRef]

35. Wang, L.; Wang, D.; Shen, Y.; Lai, X.; Guo, X. Study on properties of hydrophobic associating polymer as drag reduction agent for fracturing fluid. J. Polym. Res. 2016, 23, 235. [CrossRef]

36. Reinicke, A.; Rybacki, E.; Stanchits, S.; Huenges, E.; Dresen, G. Hydraulic fracturing stimulation techniques and formation damage mechanisms-Implications from laboratory testing of tight sandstone-proppant systems. Chem. Erde-Geochem. 2010, 70, 107-117. [CrossRef]

37. Goel, N.; Shah, S.N.; Grady, B.P. Correlating viscoelastic measurements of fracturing fluid to particles suspension and solids transport. J. Petrol. Sci. Eng. 2002, 35, 59-81. [CrossRef]

38. Zhang, Y.M.; An, P.Y.; Liu, X.F. A “worm"-containing viscoelastic fluid based on single amine oxide surfactant with an unsaturated $C_{22}$-tail. RSC Adv. 2015, 5, 19135-19144. [CrossRef]

39. Samuel, M.; Marcinew, R.; Al-Harbi, M.; Samuel, E.; Xiao, Z.; Ezzat, A.M.; Khamees, S.A.; Jarrett, C.; Ginest, N.H.; Bartko, K.; et al. A New Solids-Free Non-Damaging High Temperature Lost-Circulation Pill: Development and First Field Applications. In Proceedings of the SPE Middle East Oil Show, Manama, Bahrain, 9-12 June 2003.

(C) 2018 by the authors. Licensee MDPI, Basel, Switzerland. This article is an open access article distributed under the terms and conditions of the Creative Commons Attribution (CC BY) license (http://creativecommons.org/licenses/by/4.0/). 